\title{
Sciences
}

\section{A model test towards university students' cheating behaviour in the context of the theory of planned behaviour}

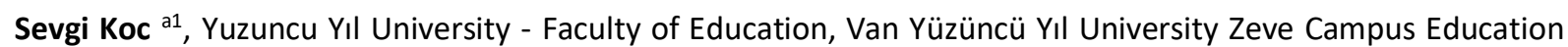
Faculty, B Blok Van 65080, Van, Turkey https://orcid.org/0000-0002-3023-4102

Hasan Basri Memduhoglu b, Siirt University- Faculty of Education, Siirt University-Kezer Campus, Faculty of Education, 56100, Siirt, Turkey https://orcid.org/0000-0001-5592-2166

\section{Suggested Citation:}

Koc, S. \& Memduhoglu, H. B., (2020). A model test towards university students' cheating behavior in the context of the theory of planned behavior. Cypriot Journal of Educational Sciences. 15(4), 727 - 748. DOI: 10.18844/cjes.v15i4.5056

Received October 25, 2019; revised February 15, 2020; accepted August 16, 2020.

${ }^{\circ} 2020$ Birlesik Dunya Yenilik Arastirma ve Yayincilik Merkezi. All rights reserved

\section{Abstract}

This study aimed to identify the causal relationships amongst attitude, subjective norms, perceived behavioural control, moral obligation and intention towards cheating by the Theory of Planned Behaviour. The study sample $(n=1,220)$ consists of senior students at the faculties of Van Yuzuncu Yil University, Turkey. The data were collected with the scales; attitude, subjective norms, perceived behavioural control, moral obligation and intention towards cheating, which were developed by researchers of the study. The data were analysed by the exploratory factor analysis, confirmatory factor analysis and path analysis. It can be concluded that the Theory of Planned Behaviour is capable of explaining the attitude, subjective norms, perceived behavioural control, moral obligation and intention variables towards cheating, and it is confirmed in a good model fit with this study. According to the path analysis results, the attitude towards cheating has a strong and significant effect for cheating intention, and subjective norms and the perceived behavioural control towards cheating have no significant effect for cheating intention.

Keywords: University students, cheating, planned behaviour, path analysis.

\footnotetext{
${ }^{1}$ ADDRESS FOR CORRESPONDENCE: Sevgi Koc, Yüzüncü Yıl University - Faculty of Education, Van Yüzüncü Yıl University Zeve Campus Education Faculty, B Blok Van 65080, Van, Turkey

E-mail address: sevgitoluk@hotmail.com Tel:+90 5378907317
} 
Koc, S. \& Memduhoglu, H. B., (2020). A model test towards university students' cheating behavior in the context of the theory of planned behavior. Cypriot Journal of Educational Sciences. 15(4), 727 - 748. DOI: 10.18844/cjes.v15i4.5056

\section{Introduction}

The concept of cheating, being a kind of academic dishonesty (fraud), and academic fraud is used by universities and other institutions to refer to the same meaning (Carpenter, Harding, Finelli, Montgomery \& Passow, 2006; Harding, Carpenter, Finelli \& Passow, 2004). Academic dishonesty is defined as the behaviours, by which a student aims to receive a higher grade at the expense of justice and fairness by means of cheating, preparing an assignment by cheating or plagiarism (Lin \& Wen, 2007). One of the basic concepts mentioned in the definitions related to academic dishonesty is stealing the ideas of others. Whilst Fly (1995) defined cheating to be an ethical error, it is rather a student fraud for Bowers (1964). Callahan (2004) argued that the lack of success within the competitive market and the absence of a job guarantee cause a daily disregard of ethical values. It is suggested that students tend to cheat in the hopes of a lifelong satisfactory income and comfort.

The relation between attitude and behaviour is examined in correspondence between attitudinal and behavioral entities (Ajzen \& Fishbein, 1977). The Theory of Planned Behaviour (TPB) was developed in the continuation of the studies that examine the relationship between attitude and behaviour. Ajzen $(1985 ; 1988 ; 1991)$, explain behaviour and intention, incorporated the perceived behavioural control variable into the Theory of Reasoned Action. The Theory of Planned Behaviour is to predict the extent to which a particular behaviour will occur. According to the Theory of Planned Behaviour, individuals' behaviours are under the control of certain factors. For an individual to perform a behaviour, the intention for that behaviour must first be formed, and stronger the aim for the behaviour is, the more likely it is that this behaviour will occur (Erten, 2002).

In the TPB, it is thought that the attitudes towards target behaviour and subjective norms affect the intention towards behaviour. The TPB mainly dwells on the relationship between attitude and behaviour. In this framework, the concept of attitude was discussed in detail. The TPB is discussed taking into account certain factors. These factors include attitude, perceived behavioural control, subjective norms, moral obligation and intention towards behaviour.

To explain the relationship between attitude and behaviour, Myers (1993) initiated the discussion with the question 'do attitudes inform behaviour?' Social psychologists initially argued that attitudes are crucial predictors for human behaviour; however, Festinger (1964) emphasised that the change in attitudes does not necessarily result in a change in the behaviour and that attitude is inadequate for explaining behaviour.

The factor of subjective norms focuses on the expectations of a person, institutions or organisations deemed important by the individual performing a given behaviour. If an individual is persuaded that groups that he or she finds important expect a certain behaviour, he or she feels a certain level of social pressure to conduct such a behaviour (Ajzen 1985, 1991; Fishbein \& Ajzen, 1975). The subjective norm refers to the social pressure of important reference groups or organisations that have an impact on the individual rather than performing the actual behaviour (Fishbein \& Ajzen, 1975). For instance, beliefs such as 'my friends expect me to cheat' and 'my teachers do not expect me to cheat' are thought to be subjective norms.

The perceived behavioural control variable is a variable that has been added for the model of the Theory of Reasoned Action (TRA). According to various studies carried out on the TPB there is a consensus that inclusion of perceived behavioural variable into the model contributed significantly to the prediction of behavioural intentions and behaviour. Perceived behavioural control implies to the belief of easy or difficult (Erten, 2002). If one thinks in the direction of 'cheating is easy for me', it is to assume that cheating is a behaviour that is easy in mind. Intention is an element which includes the motivational factors affecting the behaviour and demonstrates the effort and enthusiasm for performing the behaviour (Ajzen, 1991). Before a behaviour takes place, the individual is primarily considered to be an agent to form the intention of behaviour and to explain that behaviour (Fishbein \& Ajzen, 1975). The moral obligation variable added to the TPB and it is associated with reflecting 
Koc, S. \& Memduhoglu, H. B., (2020). A model test towards university students' cheating behavior in the context of the theory of planned behavior. Cypriot Journal of Educational Sciences. 15(4), 727 - 748. DOI: 10.18844/cjes.v15i4.5056

individual emotions about moral behaviour which requires responsibility (Beck \& Ajzen, 1991). It was added as a variable which determines the effect of a situation, where we develop a moral obligation on the behavioural intention.

To determine the relationship between attitude towards cheating, subjective norms and behavioural controls in the context of the TPB, under the effect of intentions emerge before an individual conducts behaviour. Inceoglu (2004, p. 112) suggested that human behaviours are initiated by a habit or imitation or by adopted social norms as well as necessities, and accordingly, the goals are manipulated towards a certain direction. It may be argued that human behaviour emerges in line with the difficulty of explaining the factors behind it, and this occurs through the individual needs, drives, learning processes, attitudes and beliefs towards the perception of the self in the context of the sociocultural factors such as family, culture and class, where a person exists as a member of society. Behavioural sciences, therefore, try to bring clarification into the subject with an interdisciplinary approach. The necessities, drives, learning process, personality, perception, attitudes and beliefs are the main psychosocial factors which shape a person's behaviour.

Beck \& Ajzen (1991) suggested that the moral obligation dimension which is included in the TPB is not the most significant factor in predicting the intention towards cheating; however, it is still crucial for predicting the cheating behaviour. Harding, Mayhew, Finelli \& Carpenter (2007) investigated the cheating behaviours of 527 students and student groups of three different fields with the TPB. According to the results of the study, those with lower moral obligation were inclined towards the higher levels of cheating. They have found that the level of moral obligation does not significantly predict the act of cheating. Chudzicka-Czupala et al. (2016), in their study, discussed the cheating behaviour with a study conducted in seven different countries with the TPB. Beck \& Ajzen (1991), in their study, argued that the modified version of the TPB is the most effective model to explain the intention towards cheating. Yang (2012), in his study with 205 Chinese students studying management, discussed the cheating behaviour with the TPB, it was found that attitude, perceived behavioural control and subjective norms are in a positive connection with the intention to cheat and that the perceived behavioural control has a valid effect on the cheating behaviour.

Considering the results obtained from these studies, it was seen that the attitude towards cheating affects the intention of cheating behaviour. This study was conducted to find out whether the TPB may explain cheating behaviour.

With this study, it was aimed to test the cheating behaviour in the context of the TPB with models consisting of causal relationships. It is aimed to give answers to the following questions:

1. With the TPB, at which level are the university students' attitudes, subjective norms, perceived behavioural controls, moral obligations and intentions towards cheating?

2. With the TPB, how are the causal relationships of university students amongst the attitude, perceived behavioural control, subjective norms and moral obligation and intention towards cheating?

\section{Method}

With the TPB, behaviours towards cheating were tested by means of structural equation modelling and it consists of model tests, in which the relationship between the variables for cheating and reasons is examined.

\subsection{Study group}

The study included two sample groups. The first phase of the study included a study group ( $n$ $=467$ ) consisting of senior year students studying at the faculties of Van Yuzuncu Yil University, Turkey, in the academic year 2016-2017, whereas the second phase included a sample group $(n=$ 1,220 ) gathered for the confirmatory factor analysis (CFA) and path analysis.

\subsection{Data collection tools}


Koc, S. \& Memduhoglu, H. B., (2020). A model test towards university students' cheating behavior in the context of the theory of planned behavior. Cypriot Journal of Educational Sciences. 15(4), 727 - 748. DOI: 10.18844/cjes.v15i4.5056

'Attitude towards cheating scale', 'perceived behavioural control towards cheating scale', 'subjective norms towards cheating scale','moral obligation towards cheating scale' and 'intention towards cheating scale' were used as the measurement tools.

The following six scale forms were developed in the context of the TPB: attitude, subjective norms, perceived behavioural control, moral obligation and intention towards cheating. The data were developed by the researchers with the help of validity and reliability analysis.

\subsection{Data analysis}

In this study, the exploratory factor analysis (EFA) and CFA were conducted for the analyses of scales for cheating developed in the context of the TPB. The goodness of fit of the model was analysed by means of $\mathbf{X}^{2}$ (Chi-square goodness of fit), goodness of fit index (GFI), comparative fit index (CFI), normed fit index (NFI), root mean square residuals (RMR) and root mean square error of approximation (RMSEA) values. For the reliability of the scale items obtained through EFA analysis, the internal consistency coefficient Cronbach's alpha $(\alpha)$ was calculated.

Items pertinent to attitude towards cheating scale were represented by $T 1, \ldots$ and $T 7$; the items pertinent to the subjective norms towards cheating scale by ON1, ON2, ON3, ON4, ON5 and ON6; the items pertinent to the perceived behavioural facility scale by ADK1,.., and ADK8; items pertinent to the moral obligation towards cheating scale by AS1, AS2, AS3, AS4 and AS5 and the items pertinent to intention towards cheating scale by N1, N2, N3, N4, N5, N6 and N7. The model shown in Figure 1 is a version of the TPB.

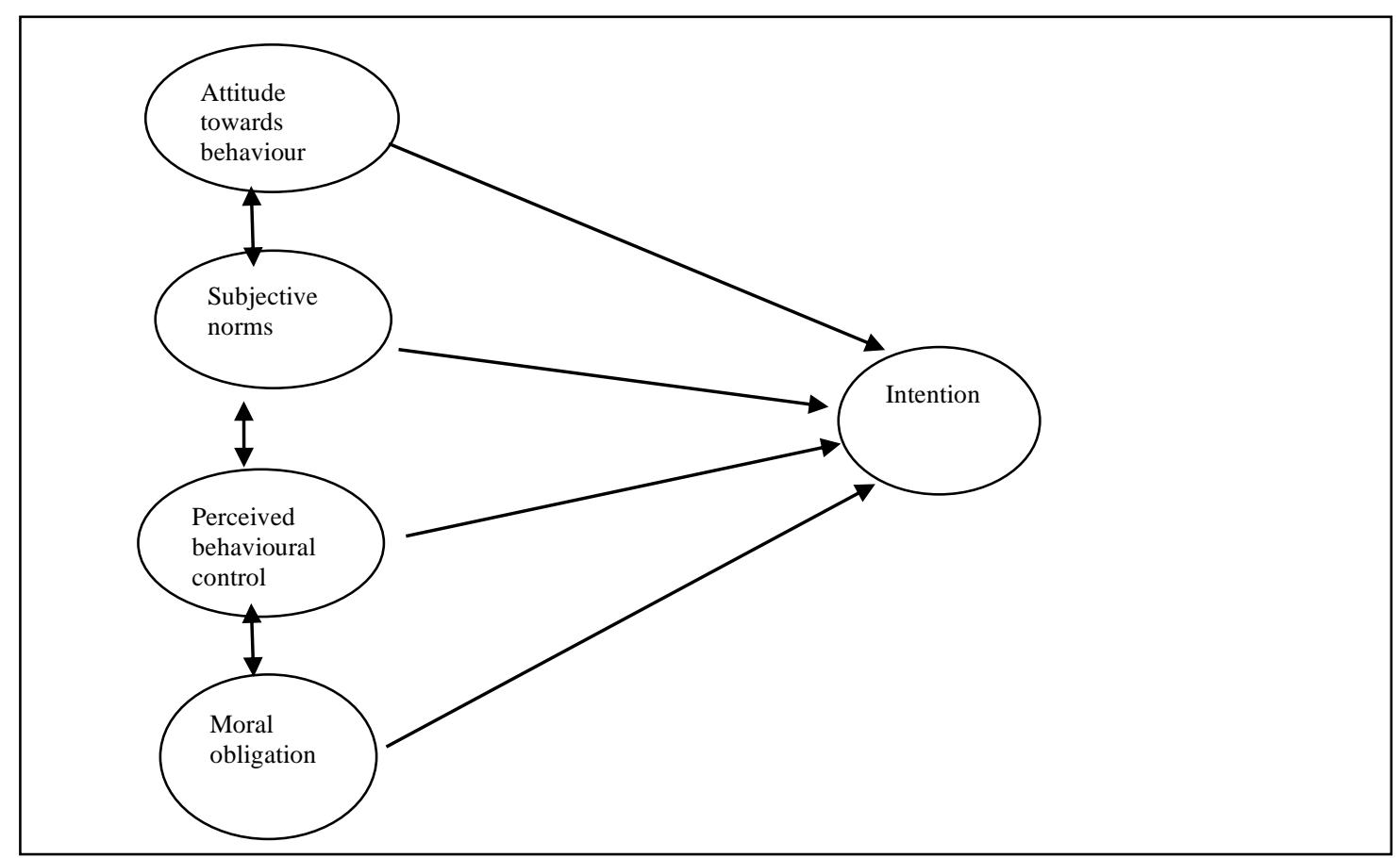

Figure 1. A version of the TPB

\section{Results}

In this chapter, model test findings of five different scales developed with the context of TPB are included. Model 1, Model 2 and Model 4 consist of the confirmatory factor models of structural equation modelling. Model 3 and Model 5 consist of path analyses.

Regarding the question 'with the context of the TPB, at which level are the attitudes, behavioural controls, subjective norms, moral obligations and intentions of university students towards cheating?' standard deviation and arithmetic mean values were calculated by the data on the total scores and sub-dimensions of the scales developed with the context of the TPB. 
Koc, S. \& Memduhoglu, H. B., (2020). A model test towards university students' cheating behavior in the context of the theory of planned behavior. Cypriot Journal of Educational Sciences. 15(4), 727 - 748. DOI: 10.18844/cjes.v15i4.5056

Table 1. Descriptive statistics of scales towards cheating with the context of the TPB $(n=1,220)$

\begin{tabular}{|c|c|c|c|c|}
\hline Variable & $N$ & $\overline{\mathbf{x}}$ & $\mathrm{df}$ & Level \\
\hline Attitude towards cheating & 1,220 & 2.76 & 1.64 & Low \\
\hline Subjective norms towards cheating & 1,220 & 4.14 & 1.74 & Medium \\
\hline $\begin{array}{l}\text { Perceived behavioural facilitators } \\
\text { towards cheating }\end{array}$ & 1,220 & 2.97 & 1.67 & Low \\
\hline $\begin{array}{l}\text { Perceived behavioural constraints } \\
\text { towards cheating }\end{array}$ & 1,220 & 3.93 & 1.84 & Medium \\
\hline Moral obligation towards cheating & 1,220 & 4.70 & 2.14 & High \\
\hline Intention towards cheating & 1,220 & 2.65 & 1.67 & Low \\
\hline
\end{tabular}

$3.55)$, moderate (0.56-4.40), slightly high (4.41-5.25), high (5.26-6.10) and very high (6.11-7.00)

As shown in Table 1, it can be said that university students $(\overline{\mathbf{X}}=2.76)$ have a medium level attitude towards cheating. For the items 'I believe that cheating contributes to academic success', 'cheating has a positive effect on my exam grades', 'cheating is important to me', 'I see it necessary to cheat when I cannot answer a question', 'I find cheating entertaining', 'I think cheating gives me an advantage' and 'It is logical to cheat within this exam system', students were found to have a moderate level of attitude.

It consists of the analysis findings on the question 'with the context of the TPB, how are the relationships amongst dimensions and components pertinent to the attitudes, subjective norms, perceived behavioural facilitators and intentions of university students towards cheating?' obtained through the CFA Model 1 test. It was observed that the data were normally distributed, and the analysis was conducted by means of maximum likelihood and covariance matrix. Table 2 shows, according to CFA, the findings obtained from Model 1 and the scales which were tested by EFA.

Table 2. Model-1: The findings of CFA statistics

\begin{tabular}{|c|c|c|c|c|c|c|}
\hline Factor & $\begin{array}{r}\text { Factor } \\
\text { load }\end{array}$ & $\begin{array}{r}\text { Error } \\
\text { variance }\end{array}$ & $R^{2}$ & $\begin{array}{l}\text { Item-total } \\
\text { correlation }\end{array}$ & $\overline{\mathbf{x}}$ & $\mathrm{df}$ \\
\hline
\end{tabular}

Attitude towards cheating $\alpha=0.87$

$\begin{array}{lllllll}\text { T1 } & 0.66 & 0.57 & 0.43 & 0.628 & 2.51 & 2.10 \\ \text { T2 } & 0.72 & 0.58 & 0.52 & 0.671 & 3.59 & 2.29 \\ \text { T3 } & 0.69 & 0.52 & 0.48 & 0.643 & 2.01 & 1.78 \\ \text { T4 } & 0.75 & 0.43 & 0.57 & 0.684 & 2.89 & 2.18 \\ \text { T5 } & 0.72 & 0.49 & 0.51 & 0.658 & 2.34 & 2.06 \\ \text { T6 } & 0.76 & 0.42 & 0.58 & 0.723 & 2.72 & 2.16 \\ \text { T7 } & 0.71 & 0.49 & 0.51 & 0.658 & 3.25 & 2.48\end{array}$

Subjective norms towards cheating $\alpha=0.82$

$\begin{array}{lllllll}\text { ON1 } & 0.54 & 0.71 & 0.29 & 0.513 & 3.91 & 2.41 \\ \text { ON2 } & 0.50 & 0.75 & 0.25 & 0.473 & 3.06 & 2.13 \\ \text { ON3 } & 0.79 & 0.37 & 0.63 & 0.690 & 4.61 & 2.43 \\ \text { ON4 } & 0.72 & 0.48 & 0.52 & 0.666 & 4.23 & 2.37 \\ \text { ON5 } & 0.70 & 0.51 & 0.49 & 0.605 & 4.31 & 2.45 \\ \text { ON6 } & 0.75 & 0.43 & 0.57 & 0.654 & 4.60 & 2.39\end{array}$

Perceived behavioural facilitators towards cheating $\alpha=0.92$

$\begin{array}{lllllll}\text { K1 } & 0.70 & 0.51 & 0.49 & 0.645 & 2.95 & 2.09 \\ \text { K2 } & 0.83 & 0.31 & 0.69 & 0.772 & 2.78 & 2.08 \\ \text { K3 } & 0.88 & 0.22 & 0.78 & 0.824 & 2.83 & 2.11\end{array}$


Koc, S. \& Memduhoglu, H. B., (2020). A model test towards university students' cheating behavior in the context of the theory of planned behavior. Cypriot Journal of Educational Sciences. 15(4), 727 - 748. DOI: 10.18844/cjes.v15i4.5056

$\begin{array}{lllllll}\text { K4 } & 0.77 & 0.40 & 0.60 & 0.726 & 2.94 & 2.06 \\ \text { K5 } & 0.82 & 0.32 & 0.68 & 0.778 & 2.81 & 2.14 \\ \text { K6 } & 0.72 & 0.48 & 0.52 & 0.717 & 2.98 & 2.01 \\ \text { K7 } & 0.70 & 0.51 & 0.49 & 0.700 & 3.15 & 2.12 \\ \text { K8 } & 0.73 & 0.47 & 0.53 & 0.727 & 3.04 & 2.04\end{array}$

Intention towards cheating $\alpha=0.91$

$\begin{array}{lllllll}\text { N1 } & 0.72 & 0.49 & 0.51 & 0.665 & 3.40 & 2.41 \\ \text { N2 } & 0.68 & 0.54 & 0.46 & 0.651 & 2.18 & 1.78 \\ \text { N3 } & 0.78 & 0.39 & 0.61 & 0.754 & 2.24 & 1.86 \\ \text { N4 } & 0.83 & 0.31 & 0.69 & 0.794 & 2.50 & 2.00 \\ \text { N5 } & 0.77 & 0.41 & 0.59 & 0.730 & 2.32 & 1.90 \\ \text { N6 } & 0.82 & 0.33 & 0.67 & 0.767 & 2.94 & 2.19 \\ \text { N7 } & 0.86 & 0.26 & 0.74 & 0.819 & 2.97 & 2.24\end{array}$

As shown in Table 2, it is seen that factor loads vary between 0.50 and 0.86 . Tabachnick and Fidell (2007) suggested that the factor load of 0.71 (explains $50 \%$ of the variance) corresponds to perfect, 0.63 (describes $40 \%$ of the variance) very good, 0.55 (explains $30 \%$ of the variance) good, 0.45 (describes $20 \%$ of the variance) mediocre and 0.32 (explains $10 \%$ of the variance) translates into a poor fit. The cut-off point for the factor load values was determined to be 0.70 (Tabachnick \& Fidell, 2007). Item T1 (factor load value 0.66 ) of the attitude towards cheating Scale, items ON1 (factor load value 0.54) and ON2 (factor load value 0.50) of the subjective norms towards cheating scale and item N1 (factor load value 0.68 ) of the intention towards cheating scale were excluded from the analysis since their factor load values were below 0.70. Tabachnick \& Fidell (2007) evaluated the remaining items to be above the value of 0.70 and thus 'perfect'.

For path or standardised regression coefficients, Cohen (1988) put forth that the values below 0.10 have a poor effect, values between 0.10 and 0.50 have a medium effect, above 0.50 have a strong effect. It is seen that $B$ path coefficients (standardised regression coefficients) or factor loads had a good level of effect. Chi-square value $\boldsymbol{X}^{2}=26642,879$, and degree of freedom $\mathrm{df}$ was found to be $\mathrm{df}=344$ The fit indices for model conformity are examined, and the values obtained are shown in Table 3.

Table 3. Model-1: The findings pertinent to confirmatory analysis goodness of fit indices

\begin{tabular}{|c|c|c|c|c|c|}
\hline $\begin{array}{l}\text { Goodness } \\
\text { of fit } \\
\text { indices }\end{array}$ & Value & Perfect fit & $\begin{array}{l}\text { Acceptable/Good } \\
\text { fit }\end{array}$ & Status & Source \\
\hline $\mathrm{x}^{2} / \mathrm{df}$ & 7.68 & $\mathrm{x}^{2} / \mathrm{df} \leq 3$ & $\mathrm{x}^{2} / \mathrm{df} \leq 5$ & Poor fit & (Kline, 2011) \\
\hline RMSEA & 0.07 & RMSEA $\leq 0.05$ & RMSEA $\leq 0.08$ & Acceptable Fit & $\begin{array}{l}\text { (Hooper,Coughlan } \\
\text { \&Mullen, 2008) }\end{array}$ \\
\hline RMR & 0.27 & $\mathrm{RMR} \leq 0.05$ & $\mathrm{RMR} \leq 0.08$ & Poor fit & $\begin{array}{l}\text { (Hu \& Bentler, } \\
\text { 1999) } \\
\text { (Brown, 2006) }\end{array}$ \\
\hline $\mathrm{NFI}$ & 0.87 & $\mathrm{NFI} \geq 0.95$ & $\mathrm{NFI} \geq 0.90$ & Poor fit & $\begin{array}{l}\text { (Tabachnick } \\
\text { Fidell, 2007) }\end{array}$ \\
\hline CFI & 0.88 & $C F I \geq 0.95$ & $C F I \geq 0.90$ & Poor fit & $\begin{array}{l}\text { (Tabachnick } \\
\text { Fidell, 2007) }\end{array}$ \\
\hline GFI & 0.84 & $\mathrm{GFI} \geq 0.95$ & $\mathrm{GFI} \geq 0.90$ & Poor fit & $\begin{array}{l}\text { (Hooper et al., } \\
\text { 2008) }\end{array}$ \\
\hline
\end{tabular}

$x^{2}=2,642.879 ; \mathrm{df}=344$ 
Koc, S. \& Memduhoglu, H. B., (2020). A model test towards university students' cheating behavior in the context of the theory of planned behavior. Cypriot Journal of Educational Sciences. 15(4), 727 - 748. DOI: 10.18844/cjes.v15i4.5056

Table 3 shows that some goodness of fit indices have poor, some good and others have perfect fit values. It shows although RMSEA $=0.07 \leq 0.08$ value is within a good fit interval, other fit indices demonstrate a poor fit. As a result of the analysis, it is believed that examining the suggestions for the modification of the factor load values and model fit indices is helpful. Modification in confirmatory factor models may be due to various reasons. The number of structures in the model, the relationship of the structures with the indicators and the presence of unresolved relations between the measurement error terms may require modification. Considering all these possibilities, the redetermination of the model should be supported not only by experimental studies but also by strong ideas (Cokluk et al., 2012; Kline, 2011). Within this framework, it was found that items T1, T2 and T7 of the attitude toward cheating scale and items N1 and N7 of the intention towards cheating scale are closely related under the same latent variable in terms of content. The first CFA demonstrated that some of the items are overly associated with one another. Considering subjective norms scale towards cheating, due to the fact that ON1 and ON2 factor load values were below 0.70 of the subjective norms' scale for copying, it was subtracted from the model and CFA was re-performed.

In the context of the TPB, Figure 1 shows a schema of Model 1's standardised values of the scales towards cheating.

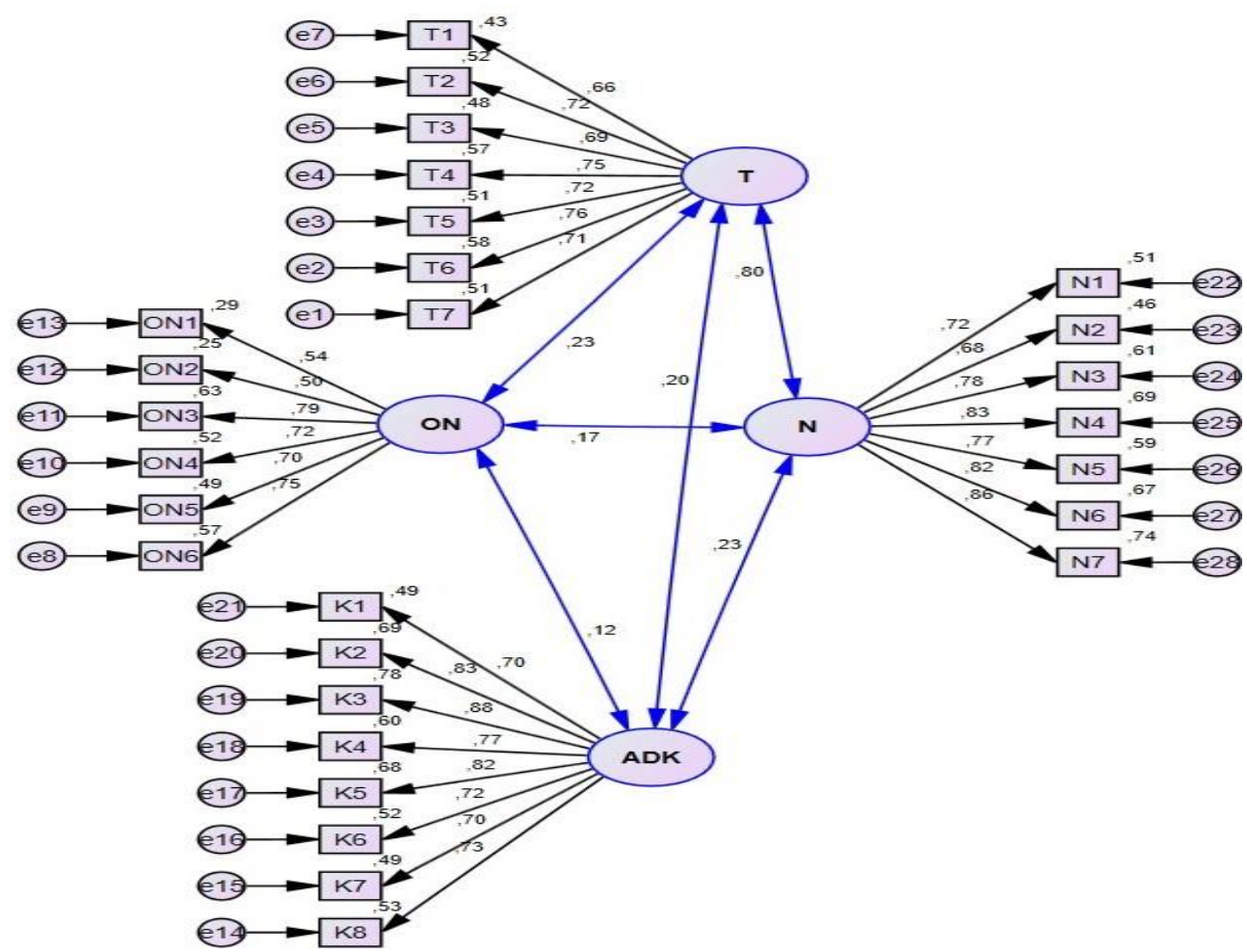

Figure 2. Standardised values of Model 1 test of scales towards cheating in the context of the TPB. T: Attitude, ON: Subjective Norms, ADK: Facility of the Perceived Behaviour, N: Intention

Figure 2 shows the Model 1 test of the scales developed in accordance with the TPB. In other words, in order to form a compatible structure between perceived behavioural facilitators, attitude, subjective norms and intention, the outputs obtained through Amos 24 Statistics Software, suggestions for modifications and the standardised regression coefficients $\boldsymbol{R}^{2}$ were evaluated within

the scope of the TPB. Items T1, T2 and T2 of the attitude towards cheating scale, items ON1, ON2 and ON5 of the subjective norms towards cheating scale, items K7 and K8 of the perceived behavioural facilitators towards cheating scale and items N2 and N7 of the intention towards cheating scale were excluded and then, it was re-tested. 
Koc, S. \& Memduhoglu, H. B., (2020). A model test towards university students' cheating behavior in the context of the theory of planned behavior. Cypriot Journal of Educational Sciences. 15(4), 727 - 748. DOI: 10.18844/cjes.v15i4.5056

It consists of the analysis findings obtained through EFA Model 2 test on the question 'in the context of the TPB, how are the relationships amongst dimensions and components pertinent to the attitudes, perceived behavioural facilitators, subjective norms and intentions of university students towards cheating?' obtained through the CFA of Model 2 test. It was observed that the data were normally distributed, and the analysis was conducted by means of maximum likelihood and covariance matrix. Table 4 shows, according to CFA, the findings obtained from Model 2 and the scales which were tested by EFA.

Table 4. Model-2: The findings of CFA statistics

\begin{tabular}{cccc}
\hline Factor & Factor load & Error variance & $\boldsymbol{R}^{2}$ \\
\hline Attitude towards cheating & & & \\
T3 & 0.73 & 0.47 & 0.53 \\
T4 & 0.73 & 0.46 & 0.54 \\
Attitude towards cheating & & & \\
T5 & 0.76 & 0.43 & 0.57 \\
T6 & 0.74 & 0.46 & 0.54 \\
Subjective norms towards cheating & & & \\
ON3 & 0.84 & 0.29 & 0.71 \\
ON4 & 0.70 & 0.52 & 0.48 \\
ON6 & 0.72 & 0.49 & 0.51 \\
K1 & 0.71 & & \\
K2 & 0.85 & 0.49 & 0.51 \\
K3 & 0.91 & 0.28 & 0.72 \\
K4 & 0.78 & 0.17 & 0.83 \\
K5 & 0.82 & 0.39 & 0.61 \\
K6 & 0.65 & 0.33 & 0.67 \\
Intention towards cheating & & 0.48 & 0.42 \\
N3 & 0.80 & & \\
N4 & 0.86 & 0.37 & 0.63 \\
N5 & 0.77 & 0.26 & 0.74 \\
N6 & 0.82 & 0.40 & 0.60 \\
& & 0.23 & 0.67 \\
\hline
\end{tabular}

Table 4 shows that factor loads range between 0.65 and 0.91 . The factor load value of $K 6$ item of the perceived facilitators towards the cheating scale is very good with 0.65 , and the factor load value of other items has a perfect factor load value. Chi-square value $\boldsymbol{X}^{2}=522.872$, and $\mathrm{df}$ was found to be $d f=113$. The fit indices for model conformity are examined, and the values obtained are shown in Table 5.

Table 5. Model-2: The findings pertinent to path analysis goodness of fit indices

\begin{tabular}{|c|c|c|c|c|c|}
\hline $\begin{array}{c}\text { Goodness of } \\
\text { fit indices }\end{array}$ & Value & Perfect fit & $\begin{array}{l}\text { Acceptable/Good } \\
\text { fit }\end{array}$ & Status & Source \\
\hline $\mathrm{x}^{2} / \mathrm{df}$ & 4.62 & $\mathrm{x}^{2} /{ }_{\mathrm{df}} \leq 2$ & $\mathrm{x}^{2} / /_{\mathrm{df}} \leq 5$ & $\begin{array}{l}\text { Acceptable/Good } \\
\text { fit }\end{array}$ & (Kline, 2011) \\
\hline RMSEA & 0.05 & RMSEA $\leq 0.05$ & RMSEA $\leq 0.08$ & Perfect fit & $\begin{array}{l}\text { (Hooper et al., } \\
\text { 2008) }\end{array}$ \\
\hline RMR & 0.17 & $\mathrm{RMR} \leq 0.5$ & $\mathrm{RMR} \leq 0.08$ & Poor fit & $\begin{array}{l}\text { (Hu \& Bentler, } \\
\text { 1999) (Brown, } \\
\text { 2006) }\end{array}$ \\
\hline $\mathrm{NFI}$ & 0.95 & $\mathrm{NFI} \geq 0.95$ & $\mathrm{NFI} \geq 0.90$ & Perfect fit & $\begin{array}{l}\text { (Sumer, 2000) } \\
\text { (Tabachnick \& }\end{array}$ \\
\hline
\end{tabular}


Koc, S. \& Memduhoglu, H. B., (2020). A model test towards university students' cheating behavior in the context of the theory of planned behavior. Cypriot Journal of Educational Sciences. 15(4), 727 - 748. DOI: 10.18844/cjes.v15i4.5056

Fidell, 2007)

$\begin{array}{cccccl}\text { CFI } & 0.96 & \mathrm{CFI} \geq 0.95 & \mathrm{CFI} \geq 0.90 & \text { Perfect fit } & \begin{array}{l}\text { (Tabachnick \& } \\ \text { Fidell, 2007) }\end{array} \\ \text { GFI } & 0.94 & \mathrm{GFI} \geq 0.95 & \mathrm{GFI} \geq 0.90 & \text { Perfect fit } & \begin{array}{l}\text { (Hooper et al., } \\ \text { 2008) }\end{array}\end{array}$

$X^{2}=522.872 ; \mathrm{df}=113$.

Table 5 shows that certain goodness of fit indices have poor, some good and others have perfect fit values. It is also observed that $\mathrm{X}^{2} / \mathrm{df}=4.62$ value is within the good fit interval, whereas $\mathrm{GFI}, \mathrm{NFI}$ and CFI values demonstrate a perfect fit. Given this finding, it can be said that the model was confirmed with a perfect fit.

In the context of the TPB, Figure 2 shows a schema of confirmatory Model 2's standardised values of the scales towards cheating.

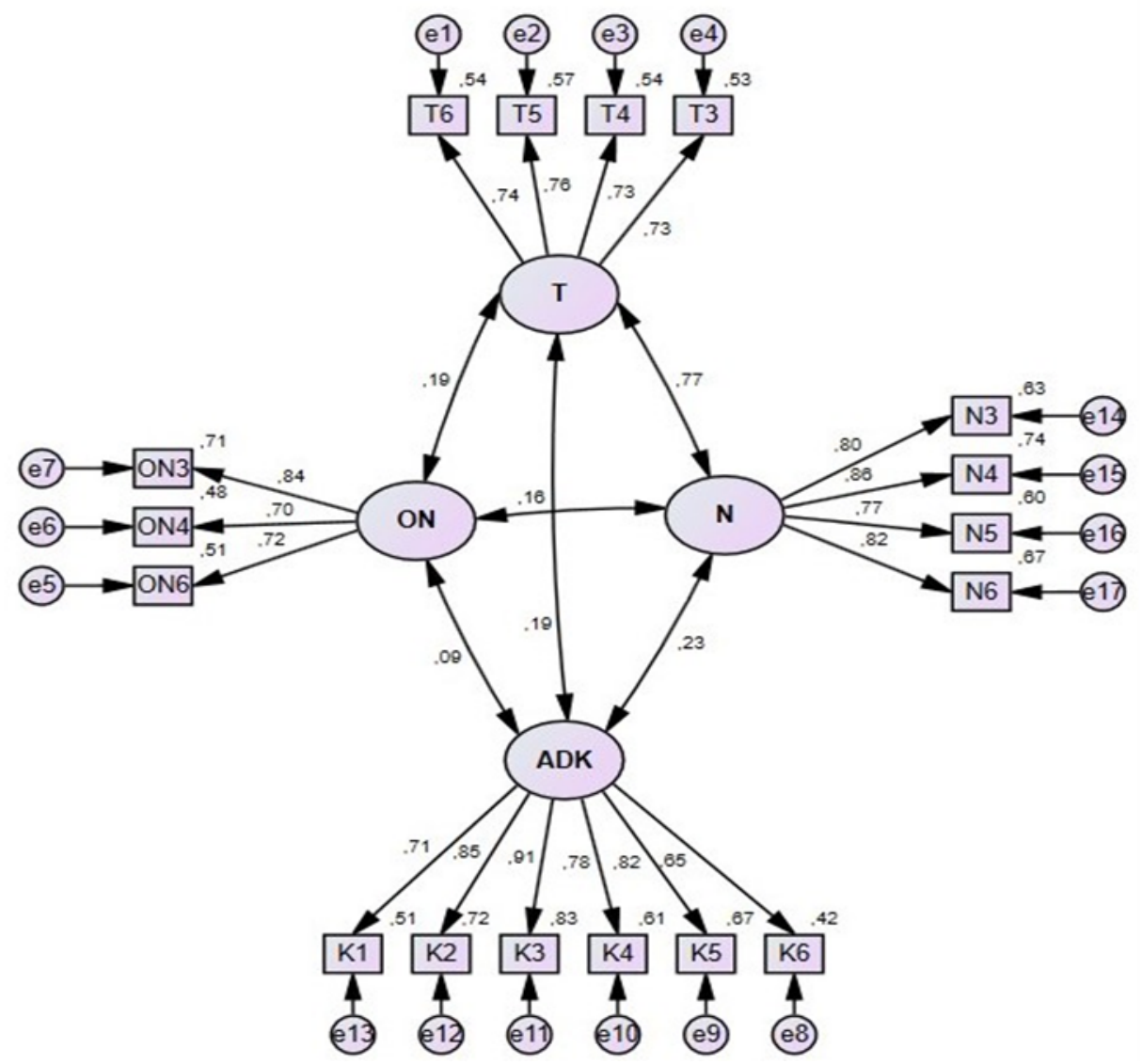

Figure 3. Standardised values of Model 2 test of scales towards cheating in the context of the TPB. T: Attitude, ON: Subjective Norm, ADK: Facility of the Perceived Behaviour, N: Intention

As for the question 'in the context of the TPB, how are the relationships amongst the attitude, subjective norms, perceived behavioural facilitators and intention dimensions towards cheating ?'; since the Model 2 is within a good/acceptable fit interval, it was analysed by means of the path analysis in the framework of Model 3 . The statistics of the findings obtained from Model 3 are seen in Table 6. 
Koc, S. \& Memduhoglu, H. B., (2020). A model test towards university students' cheating behavior in the context of the theory of planned behavior. Cypriot Journal of Educational Sciences. 15(4), 727 - 748. DOI: 10.18844/cjes.v15i4.5056

Table 6. Model-3: The findings of path analysis statistics

\begin{tabular}{cccc}
\hline \multicolumn{1}{c}{ Factor } & Factor load & Error variance & $\boldsymbol{R}^{2}$ \\
\hline Attitude towards cheating & 0.73 & 0.47 & \\
T3 & 0.73 & 0.46 & 0.53 \\
T4 & 0.76 & 0.43 & 0.57 \\
T5 & 0.74 & 0.46 & 0.54 \\
T6 & & & \\
Subjective norms towards cheating & 0.84 & 0.29 & 0.71 \\
ON3 & 0.70 & 0.42 & 0.48 \\
ON4 & 0.72 & 0.49 & 0.51 \\
ON6 & 0.71 & & \\
Perceived behavioural facilitators towards cheating & 0.49 & 0.51 \\
K1 & 0.85 & 0.28 & 0.72 \\
K2 & 0.91 & 0.17 & 0.83 \\
K3 & 0.78 & 0.39 & 0.61 \\
K4 & 0.82 & 0.33 & 0.67 \\
K5 & 0.65 & 0.48 & 0.42 \\
K6 & & & \\
Intention towards cheating & 0.80 & 0.37 & 0.63 \\
N3 & 0.86 & 0.26 & 0.74 \\
N4 & 0.77 & 0.40 & 0.60 \\
N5 & 0.82 & 0.33 & 0.67 \\
N6 & & &
\end{tabular}

Table 6 shows that factor loads vary between 0.65 and 0.91 . The factor load value of $K 6$ item of the perceived facilitators towards cheating scale is very good with 0.65 , and the factor load value of $t$ other items has a perfect factor load value. Chi-square value $\boldsymbol{X}^{2}=827,396$, and the degree of freedom df was found to be $\mathrm{df}=199$. The fit indices for model conformity are examined, and the values obtained are shown in Table 7.

Table 7. Model-3: The findings pertinent to path analysis goodness of fit indices

\begin{tabular}{|c|c|c|c|c|c|}
\hline $\begin{array}{c}\text { Goodness } \\
\text { of fit } \\
\text { indices }\end{array}$ & Value & Perfect fit & $\begin{array}{l}\text { Acceptable/Good } \\
\text { fit }\end{array}$ & Status & Source \\
\hline $\mathrm{X}^{2} / \mathrm{df}$ & 4.62 & $\mathrm{X}^{2} / \mathrm{df} \leq 2$ & $\mathrm{X}^{2} / \mathrm{df} \leq 5$ & $\begin{array}{l}\text { Acceptable/Good } \\
\text { fit }\end{array}$ & (Kline, 2011) \\
\hline RMSEA & 0.05 & $\begin{array}{l}\text { RMSEA } \leq \\
0.05\end{array}$ & RMSEA $\leq 0.08$ & Perfect fit & $\begin{array}{l}\text { (Hooper et al., 2008) } \\
\text { (Sumer, 2000) }\end{array}$ \\
\hline RMR & 0.17 & $\mathrm{RMR} \leq 0.05$ & $\mathrm{RMR} \leq 0.08$ & Poor fit & $\begin{array}{l}\text { (Hu \& Bentler, 1999) } \\
\text { (Brown, 2006) }\end{array}$ \\
\hline NFI & 0.95 & $\mathrm{NFI} \geq 0.95$ & $\mathrm{NFI} \geq 0.90$ & Perfect fit & $\begin{array}{l}\text { (Tabachnick \& Fidell, } \\
\text { 2007) }\end{array}$ \\
\hline $\mathrm{CFI}$ & 0.96 & $\mathrm{CFI} \geq 0.95$ & $\mathrm{CFI} \geq 0.90$ & Perfect fit & (Sumer, 2000) \\
\hline GFI & 0.94 & $\mathrm{GFI} \geq 0.95$ & $\mathrm{GFI} \geq 0.90$ & Acceptable fit & (Hu \& Bentler, 1999) \\
\hline
\end{tabular}


Koc, S. \& Memduhoglu, H. B., (2020). A model test towards university students' cheating behavior in the context of the theory of planned behavior. Cypriot Journal of Educational Sciences. 15(4), 727 - 748. DOI: 10.18844/cjes.v15i4.5056

As shown in Table 7, it is seen that some goodness of fit indices have poor, some good and others have perfect fit values. Although $\mathrm{X}^{2} / \mathrm{df}=4.62$ and GFI indices had near 'good fit' values, RMR was found to be within a poor fit interval, and RMSEA, NFI and CFI indices have a perfect fit. In the context of the TPB, Figure 3 shows a schema of Model 3's standardised values of the scales towards cheating.

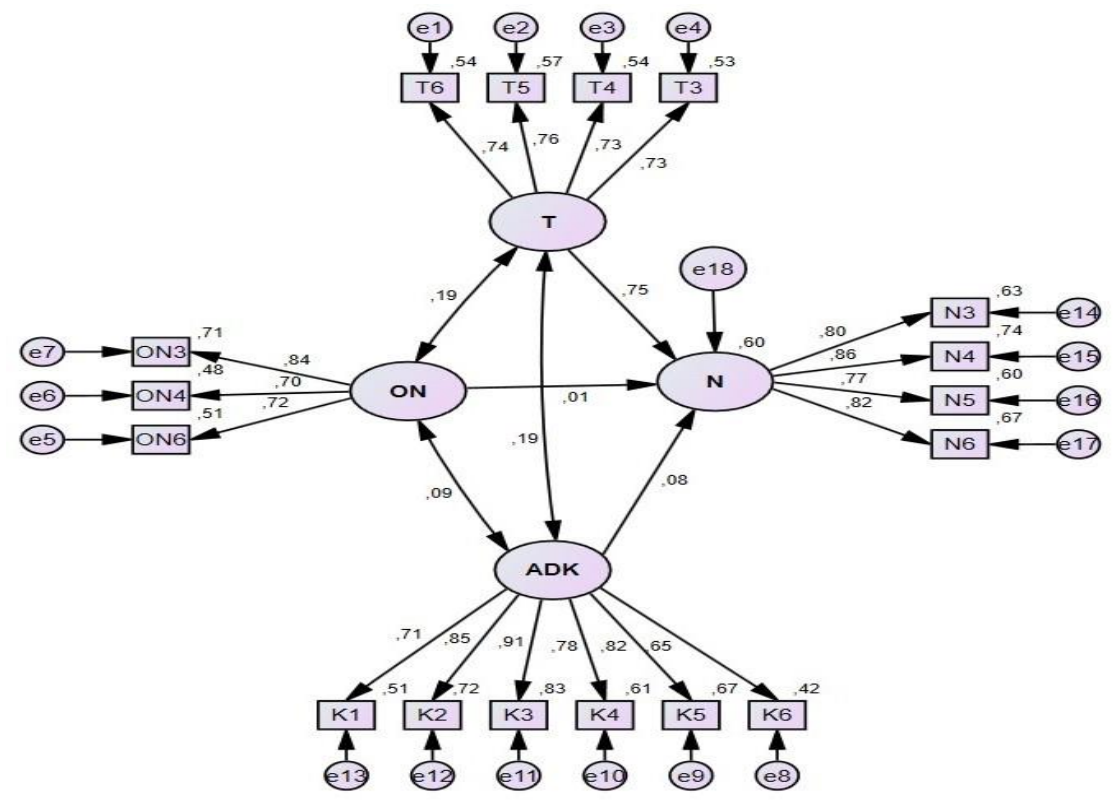

Figure 4. Standardised values of Model 3 path analysis test of scales towards cheating in the context of the TPB. T: Attitude, ON: Subjective Norm, ADK: Facility of the Perceived Behaviour, N: Intention.

It can be said that $\beta$ path coefficients (standardised regression coefficients) or factors loads had a good level of effect. When Model 3 is examined, it can be thought that attitude towards cheating $(b=0.75 ; p<0.05)$ has a significant effect on the intention towards cheating. Since $b=0.75$ path coefficient was greater than 0.50 , it could be concluded that attitude towards cheating had a significant effect with the intention towards cheating. It can be thought that perceived behavioural facilitators $(B=0.08 ; p<0.05)$ towards cheating and the subjective norms $(B=-0.01 ; p<0.05)$ towards cheating had a negative yet nonsignificant effect on the intention towards cheating.

It consists of the Model 4 analysis findings tested with CFA on the question 'in the context of the TPB, how are the relationships amongst dimensions and components pertinent to the attitudes, subjective norms, perceived behavioural facilitators and intentions of university students towards cheating?' The findings obtained from Model 4 are shown in Table 8.

Table 8. Model-4: The findings of CFA statistics

\begin{tabular}{cccc}
\hline \multicolumn{1}{c}{ Factor } & Factor load & Error variance & $\boldsymbol{R}^{2}$ \\
\hline Attitude towards cheating & & & \\
T3 & 0.73 & 0.47 & 0.53 \\
T4 & 0.74 & 0.46 & 0.54 \\
T5 & 0.76 & 0.43 & 0.57 \\
T6 & 0.74 & 0.45 & 0.55 \\
Subjective norms towards cheating & & & \\
ON3 & 0.84 & 0.29 & 0.71 \\
ON4 & 0.69 & 0.42 & 0.48 \\
ON6 & 0.72 & 0.48 & 0.52
\end{tabular}

Perceived behavioural facilitators towards cheating 
Koc, S. \& Memduhoglu, H. B., (2020). A model test towards university students' cheating behavior in the context of the theory of planned behavior. Cypriot Journal of Educational Sciences. 15(4), 727 - 748. DOI: 10.18844/cjes.v15i4.5056

$\begin{array}{llll}\text { K1 } & 0.71 & 0.49 & 0.51 \\ \text { K2 } & 0.85 & 0.28 & 0.72 \\ \text { K3 } & 0.91 & 0.17 & 0.83 \\ \text { K4 } & 0.78 & 0.39 & 0.61 \\ \text { K5 } & 0.82 & 0.33 & 0.67 \\ \text { K6 } & 0.65 & 0.48 & 0.42 \\ \text { N3 towards cheating } & & & \\ \text { N3 } & 0.79 & 0.37 & 0.63 \\ \text { N5 } & 0.86 & 0.26 & 0.74 \\ \text { N6 } & 0.77 & 0.40 & 0.60 \\ \text { obligation towards cheating } & 0.82 & 0.33 & 0.67 \\ \text { AS1 } & & & \\ \text { AS2 } & 0.83 & 0.31 & 0.69 \\ \text { AS3 } & 0.87 & 0.24 & 0.76 \\ \text { AS4 } & 0.90 & 0.10 & 0.90 \\ \text { AS5 } & 0.87 & 0.13 & 0.87 \\ \end{array}$

Table 8 shows that factor loads range between 0.65 and 0.91 . It can be argued that the factor load value of $\mathrm{K} 6$ is good with 0.65 and that of other items has a perfect factor load value. Chi-square value $\boldsymbol{X}^{2}=827,396$, and the degree of freedom df was found to be $\mathrm{df}=199$. In Model 4, unlike Model

3 , the added factor loads of moral obligation towards cheating scale varied between 0.83 and 0.90 , and this explains more than $50 \%$ of the variance. The fit indices for model conformity are examined, and the values obtained are shown in Table 9.

Table 9. Model-4: The findings pertinent to path analysis goodness of fit indices

\begin{tabular}{|c|c|c|c|c|c|}
\hline $\begin{array}{c}\text { Goodness } \\
\text { of fit } \\
\text { indices }\end{array}$ & Value & Perfect fit & $\begin{array}{c}\text { Acceptable/Good } \\
\text { fit }\end{array}$ & Status & Source \\
\hline $\mathrm{X}^{2} / \mathrm{df}$ & 4.15 & $\mathrm{X}^{2} / \mathrm{df} \leq 2$ & $\mathrm{X}^{2} / \mathrm{df} \leq 5$ & $\begin{array}{c}\text { Acceptable/Good } \\
\text { Fit }\end{array}$ & (Kline, 2011) \\
\hline RMSEA & 0.05 & RMSEA $\leq$ & RMSEA $\leq 0.08$ & Perfect fit & (Hooper et al., 2008) \\
\hline RMR & 0.17 & $\begin{array}{l}0.05 \\
R M R \leq 0.05\end{array}$ & $\mathrm{RMR} \leq 0.08$ & Poor fit & $\begin{array}{l}\text { (Hu\& Bentler, 1999) } \\
\text { (Brown, 2006) }\end{array}$ \\
\hline $\mathrm{NFI}$ & 0.95 & $\mathrm{NFI} \geq 0.95$ & $\mathrm{NFI} \geq 0.90$ & Perfect fit & (Sumer, 2000) \\
\hline CFI & 0.96 & $C F I \geq 0.95$ & $\mathrm{CFI} \geq 0.90$ & Perfect fit & (Sumer, 2000) \\
\hline GFI & 0.93 & $\mathrm{GFI} \geq 0.95$ & $\mathrm{GFI} \geq 0.90$ & Acceptable fit & $\begin{array}{l}\text { (Hu \& Bentler, 1999) } \\
\text { (Hooper et al., 2008) }\end{array}$ \\
\hline
\end{tabular}

$x^{2}=827.396 ; \mathrm{df}=199$.

Table 9 shows that some fit indices have poor, some good and others have perfect fit values. It was found that $\mathrm{X}^{2} / \mathrm{df}=4.15$ and GFI fell within a good fit interval; RMSEA, NFI and CFI within a perfect fit interval and RMR was in a poor fit interval. It can be said that, in accordance with these findings, the model tested with attitude towards cheating, subjective norms towards cheating, perceived behavioural facilitators towards cheating, moral obligation towards cheating and intention towards cheating dimensions was confirmed with either good or perfect fit. 
Koc, S. \& Memduhoglu, H. B., (2020). A model test towards university students' cheating behavior in the context of the theory of planned behavior. Cypriot Journal of Educational Sciences. 15(4), 727 - 748. DOI: 10.18844/cjes.v15i4.5056

In the context of the TPB, Figure 4 shows a schema of confirmatory Model 4's standardised values of the scales towards cheating.

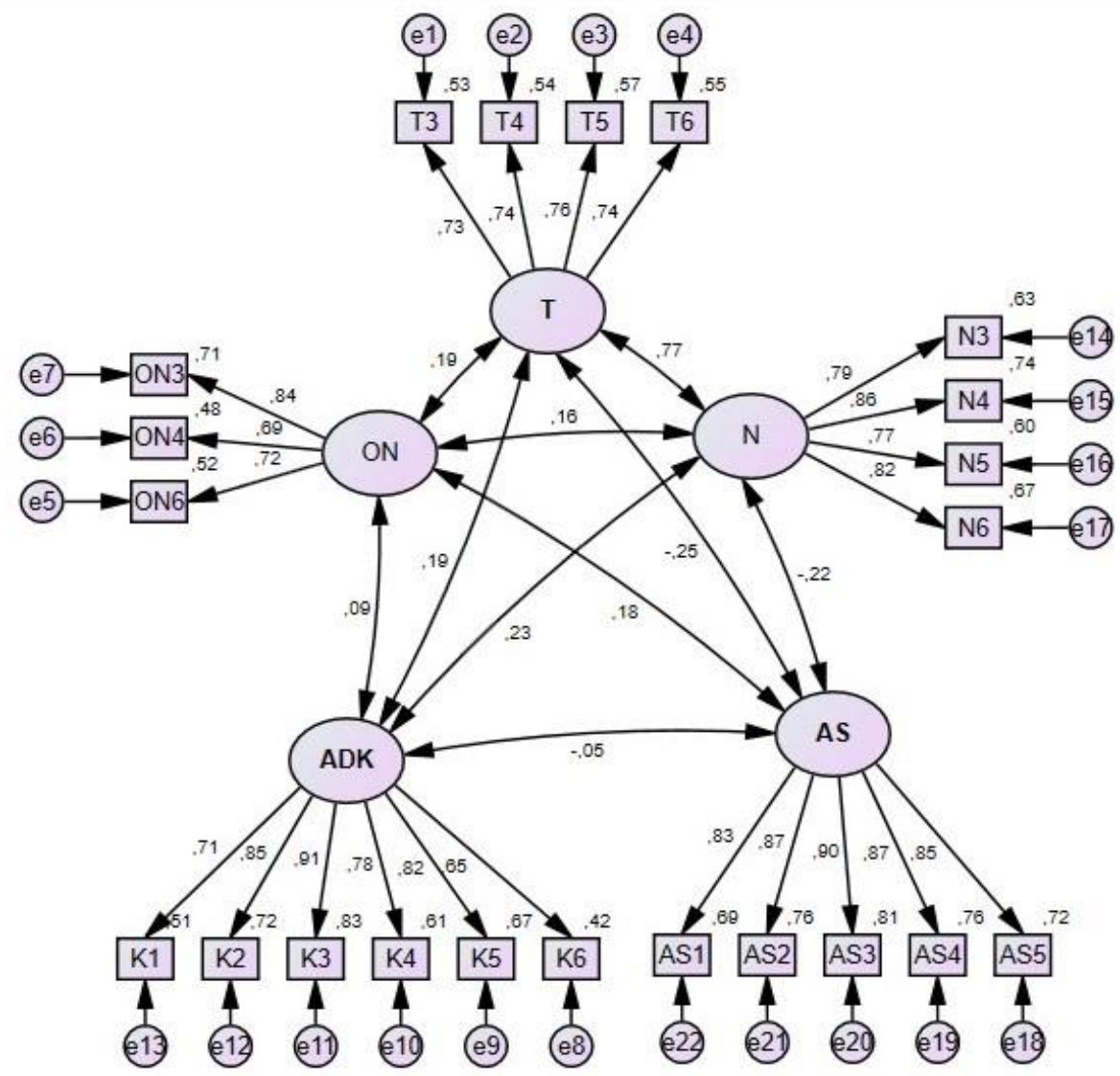

Figure 5. Standardised values of Model 4 test of scales towards cheating in the context of the TPB. T: Attitude, ON: Subjective Norm, ADK: Facility of the Perceived Behaviour, AS: Moral Obligation, N: Intention

With this study, it can be said that the model based on the attitudes towards cheating, , perceived behavioural control, subjective norms and moral obligation variables explained the intention of the model and confirmed with a good fit. It consists of the findings of Model 5's path analysis, whose acceptable fitness was ensured through EFA 'How is the relationship between the attitudes towards copying, subjective norms, perceived behavioural facilitators, moral obligation and intentions developed in the context of the TPB. The results obtained from Model 5 are shown in Table 10.

Table 10. Model-5: The findings of path analysis statistics

\begin{tabular}{cccc}
\hline \multicolumn{1}{c}{ Factor } & Factor load & Error variance & $\boldsymbol{R}^{2}$ \\
\hline Attitude towards cheating & & & \\
T3 & 0.73 & 0.47 & 0.53 \\
T4 & 0.74 & 0.46 & 0.54 \\
T5 & 0.76 & 0.43 & 0.57 \\
T6 & 0.74 & 0.45 & 0.55 \\
Attitude towards cheating & & & \\
ON3 & 0.84 & 0.29 & 0.71 \\
ON4 & 0.69 & 0.42 & 0.48 \\
ON6 & 0.72 & 0.48 & 0.52
\end{tabular}

Perceived behavioural facilitators towards cheating 
Koc, S. \& Memduhoglu, H. B., (2020). A model test towards university students' cheating behavior in the context of the theory of planned behavior. Cypriot Journal of Educational Sciences. 15(4), 727 - 748. DOI: 10.18844/cjes.v15i4.5056

$\begin{array}{llll}\text { K1 } & 0.71 & 0.49 & 0.51 \\ \text { K2 } & 0.85 & 0.28 & 0.72 \\ \text { K3 } & 0.91 & 0.27 & 0.83 \\ \text { K4 } & 0.78 & 0.39 & 0.61 \\ \text { K5 } & 0.82 & 0.33 & 0.67 \\ \text { K6 } & 0.65 & 0.48 & 0.42 \\ \text { N3 towards cheating } & & & \\ \text { N4 } & 0.79 & 0.37 & 0.63 \\ \text { N5 } & 0.86 & 0.26 & 0.74 \\ \text { N6 } & 0.77 & 0.40 & 0.60 \\ \text { obligation towards cheating } & 0.82 & 0.33 & 0.67 \\ \text { AS1 } & & & \\ \text { AS2 } & 0.83 & 0.31 & 0.69 \\ \text { AS3 } & 0.87 & 0.24 & 0.76 \\ \text { AS4 } & 0.90 & 0.19 & 0.81 \\ \text { AS5 } & 0.87 & 0.24 & 0.76 \\ \end{array}$

Table 10 shows that factor loads vary between 0.65 and 0.91 . It is seen that the factor load value of $\mathrm{K} 6$ is good with 0.65 and that of other items has a perfect factor load value. Chi-square value $\boldsymbol{X}^{2}=827,396$, and the degree of freedom df was found to be $\mathrm{df}=199 \mathrm{In}$ Model 4, unlike Model 3, the added factor loads of moral obligation towards cheating scale varied between 0.83 and 0.90 , and this explains more than $50 \%$ of the variance. The fit indices for model conformity are examined, and the values obtained are shown in Table 11.

Table 11: Model-5: The findings pertinent to path analysis goodness of fit indices

\begin{tabular}{|c|c|c|c|c|c|}
\hline $\begin{array}{l}\text { Goodness of } \\
\text { fit indices }\end{array}$ & Value & Perfect fit & $\begin{array}{l}\text { Acceptable/Good } \\
\text { fit }\end{array}$ & Status & Source \\
\hline $\mathrm{X}^{2} / \mathrm{df}$ & 4.15 & $\mathrm{X}^{2} / \mathrm{df} \leq 2$ & $\mathrm{X}^{2} / \mathrm{df} \leq 5$ & $\begin{array}{l}\text { Acceptable/Good } \\
\text { fit }\end{array}$ & (Kline,2011) \\
\hline RMSEA & 0.05 & RMSEA $\leq 0.05$ & RMSEA $\leq 0.08$ & Perfect fit & (Sumer, 2000) \\
\hline RMR & 0.17 & $\mathrm{RMR} \leq 0.05$ & $\mathrm{RMR} \leq 0.08$ & Poor fit & (Brown, 2006) \\
\hline NFI & 0.95 & $\mathrm{NFI} \geq 0.95$ & $\mathrm{NFI} \geq 0.9$ & Perfect fit & (Sumer, 2000) \\
\hline CFI & 0.96 & $\mathrm{CFI} \geq 0.95$ & $\mathrm{CFI} \geq 0.90$ & Perfect fit & $\begin{array}{l}\text { (Tabachnick \& } \\
\text { Fidell, 2007) }\end{array}$ \\
\hline GFI & 0.93 & $\mathrm{GFI} \geq 0.95$ & $\mathrm{GFI} \geq 0.90$ & $\begin{array}{l}\text { Acceptable/Good } \\
\text { fit }\end{array}$ & $\begin{array}{l}\text { (Hu \& Bentler, } \\
\text { 1999) }\end{array}$ \\
\hline
\end{tabular}

$X^{2}=827.396 ; \mathrm{df}=199$.

As shown in Table 11, it is seen that some goodness of fit indices have poor, some good and others have perfect fit values. Although $\mathrm{X}^{2} / \mathrm{df}=4.15$ and GFI indices had values near good fit, RMR was found to be within poor fit interval and RMSEA, NFI and CFI indices showed perfect fit.

In the context of the TPB, Figure 5 shows a schema of Model 5's standardised values of the scales towards cheating. 
Koc, S. \& Memduhoglu, H. B., (2020). A model test towards university students' cheating behavior in the context of the theory of planned behavior. Cypriot Journal of Educational Sciences. 15(4), 727 - 748. DOI: 10.18844/cjes.v15i4.5056

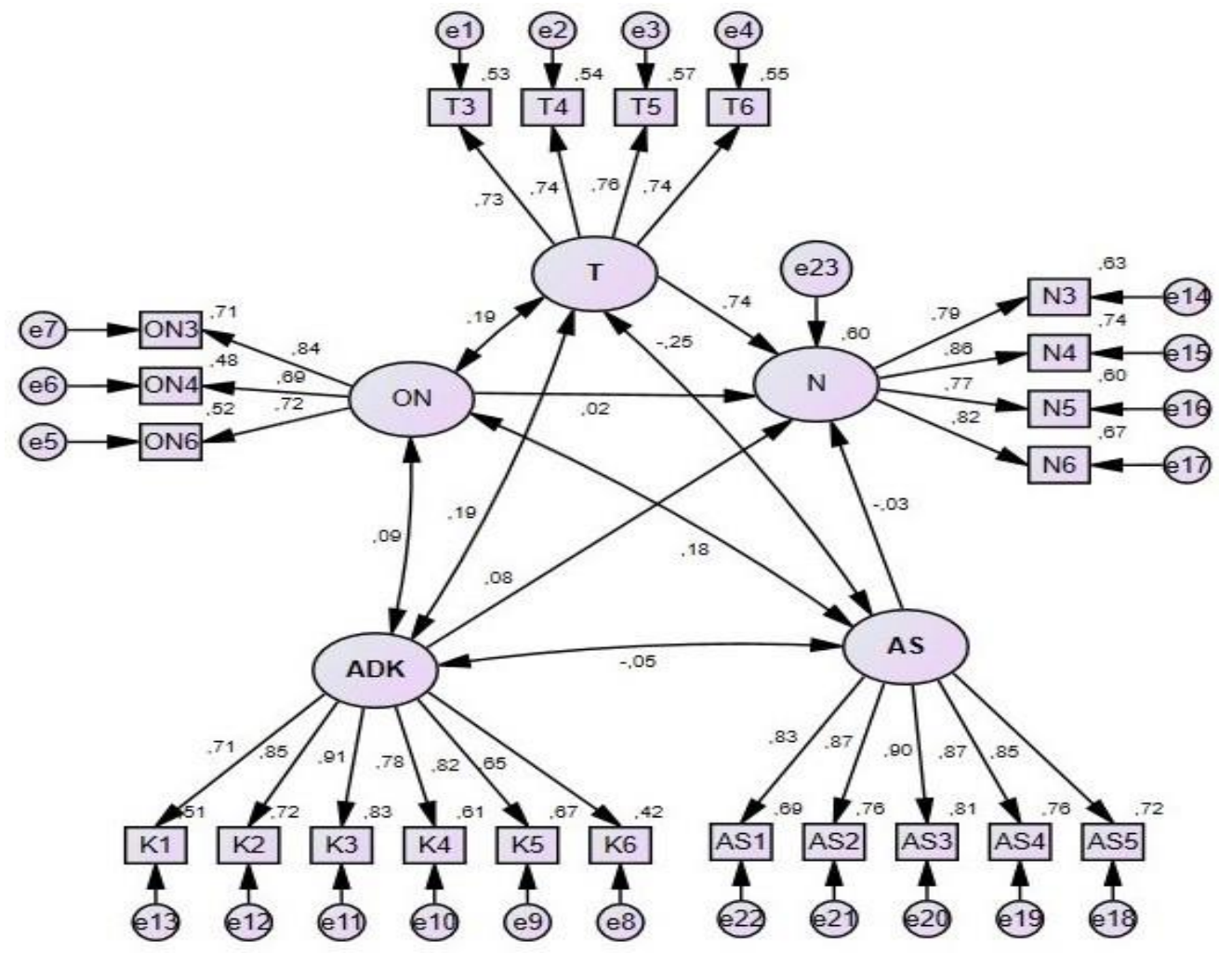

Figure 6. Standardised values of Model 5 test path analysis of scales towards cheating in the context of the TPB. T: Attitude, ON: Subjective Norm, ADK: Facility of the Perceived Behaviour, AS: Moral Obligation, $\mathrm{N}$ : Intention

Figure 6 shows that $\beta$ path coefficients (standardised regression coefficients) or factors loads have a good level of effect. When Model 5 is examined, it is seen that attitude towards cheating $(B=$ $0.74 ; p<0.05$ ) has a significant effect on the intention towards cheating. Since $b=0.75$ path coefficient was greater than 0.50 , it can be concluded that attitude towards cheating has a significant effect on the intention towards cheating. It can be thought that the perceived behavioural facilitators $(b=0.08 ; p<0.05)$ towards cheating and the moral obligation $(b=-0.03 ; p<0.05)$ towards cheating have a negative yet nonsignificant effect on the intention towards cheating. It can be argued that students who see cheating as moral behaviour do not intend to cheat.

Pertinent to the scales developed in the context of the TPB, Models 2 and 4 aim to compare the fit indices of CFA, and the findings are shown in Table 12.

Table 12. Model-2 and Model-4: The findings pertinent to factor analysis goodness of fit indices

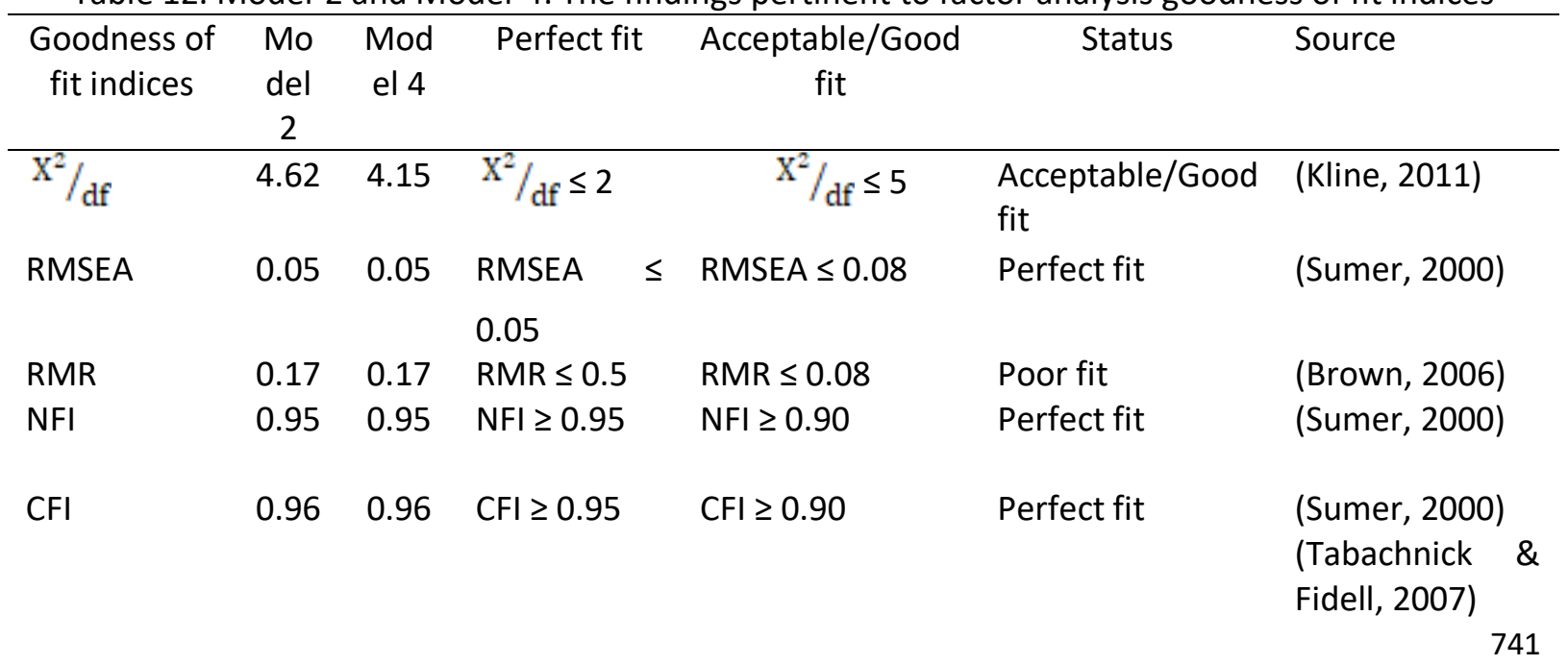


Koc, S. \& Memduhoglu, H. B., (2020). A model test towards university students' cheating behavior in the context of the theory of planned behavior. Cypriot Journal of Educational Sciences. 15(4), 727 - 748. DOI: 10.18844/cjes.v15i4.5056

$\mathrm{GFI}$

$0.940 .93 \quad \mathrm{GFI} \geq 0.95 \quad \mathrm{GFI} \geq 0.90$

Acceptable fit

(Hu \& Bentler, 1999)

(Hooper et al., 2008)

Table 12 shows that Model-2 aims to confirm the model delving into the relationship between attitudes, perceived behavioural control and intention towards cheating. In Model-4, however, the model was tested with the inclusion of moral obligation variable, unlike Model-2. When both models are examined, it is seen that RMR fit index is within a poor fit interval; GFI is within a good fit interval and RMSEA, NFI and CFI are confirmed as the perfect fit. It is also observed that, when both models are examined, the attitude towards cheating $(B=0.77 ; p<0.05)$ has a significant effect on the intention to cheat. It was found that subjective norms and the perceived behavioural facilitators do not have a significant effect on intention $(B<0.50 ; p<0.05)$. It can be argued that, in Model 4 , unlike Model-2, there is no significant negative effect $(B<0.50 ; p<0.05)$ with attitude and behavioural facilitators. It can be said that subjective norms and moral obligation have a positive yet lower $(B<0.50 ; p<0.05)$ effect.

Table 13. Model-3 and Model-5: The findings pertinent to path analysis goodness of fit indices

\begin{tabular}{|c|c|c|c|c|c|c|}
\hline $\begin{array}{l}\text { Goodness } \\
\text { of fit } \\
\text { indices }\end{array}$ & $\begin{array}{c}\text { Model } \\
3\end{array}$ & $\begin{array}{l}\text { Model } \\
5\end{array}$ & $\begin{array}{l}\text { Perfect } \\
\text { fit }\end{array}$ & $\begin{array}{l}\text { Acceptable/Good } \\
\text { fit }\end{array}$ & Status & Source \\
\hline $\mathrm{X}^{2} / \mathrm{df}$ & 4.62 & 4.15 & $\begin{array}{l}\mathrm{X}^{2} / \mathrm{df} \\
\leq 2\end{array}$ & $\mathrm{x}^{2} / \mathrm{df} \leq 5$ & $\begin{array}{l}\text { Acceptable/Good } \\
\text { fit }\end{array}$ & (Kline, 2011) \\
\hline RMSEA & 0.05 & 0.05 & $\begin{array}{l}\text { RMSEA } \\
\leq 0.05\end{array}$ & RMSEA $\leq 0.08$ & Perfect fit & $\begin{array}{l}\text { (Hooper et al., } \\
\text { 2008) } \\
\text { (Sumer, 2000) }\end{array}$ \\
\hline RMR & 0.17 & 0.17 & $\begin{array}{l}\text { RMR } \leq \\
0.05\end{array}$ & $\mathrm{RMR} \leq 0.08$ & Poor fit & $\begin{array}{l}\text { (Hu \& Bentler, } \\
\text { 1999) } \\
\text { (Brown, 2006) }\end{array}$ \\
\hline $\mathrm{NFI}$ & 0.95 & 0.95 & $\begin{array}{l}\mathrm{NFI} \geq \\
0.95\end{array}$ & $\mathrm{NFI} \geq 0.90$ & Perfect fit & $\begin{array}{l}\text { (Sumer, 2000) } \\
\text { (Tabachnick } \\
\text { Fidell, 2007) }\end{array}$ \\
\hline CFI & 0.96 & 0.96 & $\begin{array}{l}\text { CFI } \geq \\
0.95\end{array}$ & $\mathrm{CFI} \geq 0.90$ & Perfect fit & (Sumer, 2000) \\
\hline GFI & 0.94 & 0.93 & $\begin{array}{l}\mathrm{GFI} \geq \\
0.95\end{array}$ & $\mathrm{GFI} \geq 0.90$ & $\begin{array}{l}\text { Acceptable/Good } \\
\text { fit }\end{array}$ & $\begin{array}{l}\text { (Hu \& Bentler, } \\
\text { 1999) } \\
\text { (Hooper et al., } \\
2008)\end{array}$ \\
\hline
\end{tabular}

Table 13 shows that, for both models, it is seen that RMR fit index is within a poor fit interval; GFI is within a good fit interval and RMSEA, NFI and CFI are confirmed as the perfect fit. It is also seen that, when both models are examined, the attitude towards cheating $\left(b_{3}=0.75\right.$ and $B_{5}=0.74 ; p<$ 0.05 ) has a significant effect on the intention to cheat. When both models are examined, it was found that subjective norms and the perceived behavioural facilitators do not have a significant effect on intention $\left(B_{3}\right.$ and $\left.B_{5}<0.50 ; p<0.05\right)$. It can be said that, in Model 5 , unlike Model-3, there is no negative yet significant effect $(B<0.50 ; p<0.05)$ of moral obligation. Both models found the variance $\boldsymbol{R}^{2}=0.60$. It was found that there was no significant difference between Model-3 and Model-5 and that attitude towards cheating is a significant variable in predicting the intention towards cheating. 
Koc, S. \& Memduhoglu, H. B., (2020). A model test towards university students' cheating behavior in the context of the theory of planned behavior. Cypriot Journal of Educational Sciences. 15(4), 727 - 748. DOI: 10.18844/cjes.v15i4.5056

\section{Discussion}

The results are obtained from the scales of the attitude, subjective norms, perceived behavioural facilitators, moral obligation and intention towards cheating, and the students had a medium level of attitude towards cheating. It was concluded that there are medium-level attitudes towards cheating due to the perception that it contributes to academic success, has a positive effect on examination grades, is a necessity for the difficult questions in the examinations, gives one an upper hand and is a logical action. The subjective norms of the students towards cheating were found to have a moderate effect along with the factors such as the obstructive practices of the faculty administration, peer attitudes, the respect of the faculty member, the attitude of the supervisors and the importance given to the course. Factors such as determination in cheating, knowing how to cheat, making good use of cheating techniques, cheating in cooperation with peers, cheating skills and copying materials have been found to facilitate cheating. Factors such as lecturers' negative attitude towards copying and examination style make it difficult for students to cheat.

The students considered the cheating behaviour as unrespectful to the labour of a peer, a conscientious problem, a behaviour that leads to injustice, a violation of self-respect and a breach of the principles of morality. In other words, it was observed that university students perceived cheating behaviour as high-level and non-moral behaviour. It is thought that the role model lecturers conduct activities using learning approaches that are appropriate for ethical values and will facilitate the acquisition of moral obligation and ethical responsibility. In addition, it was concluded that the levels of intention to prepare for cheating, taking risks, planning with friends, seeking opportunities and encouraging were also at a moderate level.

It is concluded that the moral obligation variable has a positive yet nonsignificant relationship with the subjective norms' variable, whereas it was found to have a negative and nonsignificant relationship with other variables. Beck and Ajzen (1991) put that the moral obligation factor, in a version of the TPB, is not the most significant factor in predicting the intention towards cheating; however, it is crucial for predicting the cheating behaviour. In this study, however, it can be said that moral obligation has a negative yet nonsignificant effect on intention. Harding et al. (2007), conducted a study with 527 students and student groups from three different fields, by students lean towards the higher levels of cheating with low levels of moral obligation. The conclusion that the moral obligation dimension does not significantly predict cheating corresponds to the results of this study.

Chudzicka-Czupala et al. (2016) discussed the cheating behaviour through a study conducted in seven different countries with a version of the TPB. Chudzicka-Czupala et al. (2016), in their study, put forth that the version of the TPB is the most effective model to explain the intention towards cheating. Beck \& Ajzen (1991), with this study, put forth dimension for the modified version of the Planned Behaviour Theory, and the version in which the moral obligation dimension is included, is the most effective model to explain the intention towards cheating. The findings obtained from this research are examined, and it is seen that Model 5 can explain the cheating behaviour in the context of the TPB. Yang (2012), in his study with 205 Chinese students studying management, discussed the cheating behaviour with the TPB. According to the results of the study, it was found that attitude, subjective norms and perceived behavioural control are in a positive relationship with the intention to cheat and that the perceived behavioural control has a direct effect on the cheating behaviour. Kohlberg suggested that individuals who have achieved the high levels of cognitive moral development will make the right decisions by analysing ethics and ethical dilemmas better by the individuals who have attained a rather lower level of moral development (Kurpis, Beqiri \& Helgeson, 2008). In this vein, individuals with high moral responsibilities are expected to make an ethical decision, and as it is understood from this study, there is a negative relation between the moral obligation towards cheating and the intention towards cheating; in other words, it can be argued that individuals with high moral obligation do not develop intentions towards cheating. Thus, it has 
Koc, S. \& Memduhoglu, H. B., (2020). A model test towards university students' cheating behavior in the context of the theory of planned behavior. Cypriot Journal of Educational Sciences. 15(4), 727 - 748. DOI: 10.18844/cjes.v15i4.5056

also been obtained from the findings that students have high moral obligations for cheating. Nonis and Swift (2001) emphasised that ethical issues contribute not only to specific moral issues but also to the approaches that provide an aim towards an ethical value, including discussion in basic courses, to help students to appreciate the value of honesty in their own as well as others' behaviour.

In this study, model test findings of five different scales developed in the context of Planned Behaviour Theory are presented. Model 1, Model 2 and Model 4 consist of the confirmatory factor models of structural equation modelling. Model 3 and Model 5 consist of path analysis as well as the causal relationships amongst attitude, subjective norms, perceived behavioural facilitators, moral obligation and intention towards cheating. It is a process in which the direct and indirect effects between the variables in the scope of the model developed in accordance with the Theory of Planned Behaviour. Results pertinent to Model 1, 2, 3, 4 and 5 are presented as follows.

With the confirmatory factor model test carried out towards the confirmation of the scales developed in the context of the TPB, it was found that some of the fit values of the fit indices of Model 1 were within poor value intervals, and accordingly, certain items were excluded from the analysis in line with the suggestions for modification, expert opinion and theoretical framework.

It can be concluded that Model 2 is capable of explaining the attitude, subjective norms, perceived behavioural facilitators and intention variables towards cheating with the TPB in fit with one another. It was concluded that, in the framework of Model 2, the model has acceptable fit values and was confirmed within the perfect fit interval. Model 3 and the TPB, the path analysis findings for the model based suggest that the attitude towards cheating has a strong and significant effect with the intention towards cheating. The attitude towards cheating can predict the intention towards cheating. It was concluded that the facilitating effects of cheating and subjective norms for cheating have no significant effect on the intention to cheat. Moral obligation variable was incorporated into the setup of Model 4 and Model 2. CFA results along with the goodness of fit values of the model in which there were the causal relationships amongst the attitudes, subjective norms, behavioural controls, moral responsibilities and intentions of university students towards cheating demonstrate that the model was confirmed with a good fit.

Ajzen (1985; 1988; 1991), an attempt to explain behaviour and intention, incorporated the perceived behavioural control variable into the Reasoned Action Theory. The TPB was developed by Ajzen and Madden (1986) in the continuation of the TRA. In explaining the behaviours over which individuals have low self-control, the necessity of the Theory of Planned Behaviour stands out with the inadequacy of the Theory of Reasoned Action. The focus of the TPB is related to the individual's intention to display a certain behaviour. The element of intention is found crucial both for the TRA and the TPB. Taking into account the motivational factors, the intention dimension specifies how much of a hardship people will go through on their willingness to try or how much effort (Ajzen, 1991) they will have to put towards performing such behaviour. In the TPB, it is thought that attitudes towards target behaviour and subjective norms affect intention.

\section{Conclusion}

In this research, it is concluded that the students had a medium level of attitude towards cheating.

In this study, it can be said that the model based on the attitudes towards cheating, subjective norms, perceived behavioural control and moral obligation variables explained the intention towards cheating confirmed with the good model fit.

It is based on the results of the Model 4's path analysis, which is carried out by CFA conducted with Model 5. The relationship between attitudes, subjective norms, perceived behavioural control and moral obligation and intention is investigated. A positive yet non-significant relationship was found between moral obligation and subjective norms, whereas there was found a 
Koc, S. \& Memduhoglu, H. B., (2020). A model test towards university students' cheating behavior in the context of the theory of planned behavior. Cypriot Journal of Educational Sciences. 15(4), 727 - 748. DOI: 10.18844/cjes.v15i4.5056

negative and nonsignificant relationship with attitude, perceived behavioural facilitators and the intention variable.

The cheating behaviour is explained by the attitude towards cheating in the context of the TPB, subjective norms for cheating, perceived behavioural facilitators for cheating, the moral obligation for copying and intention to cheat.

It is concluded that students who consider copying behaviour as immoral do not intend to cheat and have no positive attitudes towards cheating.

It is crucial to conclude that students who consider cheating behaviour as non-ethical do not intend to cheat and have no attitudes towards cheating.

\section{Recommendations}

In the context of the TPB towards cheating scales developed in this study, it is possible to organise the studies, in which the scales for cheating are tested in different samples.

It is thought that conducting course activities as role model lecturers using learning approaches are appropriate for ethical values and will contribute to the acquisition of moral obligation and ethical responsibility.

Therefore, it should be emphasised in the lessons that cheating is a moral problem. In order to stimulate students, the students' self-regulatory skills and arrangements to increase their target orientations can make learning-teaching processes more effective, and the intention towards cheat could be diminished.

\section{References}

Ajzen, I. (1985). From intentions to actions: a theory of planned behavior. In J. Kuhl \& J. Beckmann (Eds.), Action-contro: from cognition to behavior (pp. 11-39). Heidelberg, Germany: Springer.

Ajzen, I. (1988). Attitudes, personality and behavior. Chicago, IL: Dorsey Press.

Ajzen, I. (1991). The theory of planned behavior. Organization Behavior and Human Decision Process, 50, 179211.

Ajzen, I. \& Fishbein, M. (1977). Attitude-behavior relations: a theoretical analysis and review of emprical research. Psychological Bulletin, 84(5), 888-918.

Ajzen, I. \& Madden, T. J. (1986). Prediction of goal-directed behavior: attitudes, intentions and perceived behavioral control. Journal of Experimental Social Psychology, 22, 453-474.

Beck, L. \& Ajzen, I. (1991). Predicting dishonest actions using the theory of planned behavior. Journal of Research in Personality, 25, 285-301.

Bowers, W. J. (1964). Student dishonesty and its control in college. New York: Bureau of Applied Social Research, Columbia University. 
Koc, S. \& Memduhoglu, H. B., (2020). A model test towards university students' cheating behavior in the context of the theory of planned behavior. Cypriot Journal of Educational Sciences. 15(4), 727 - 748. DOI: 10.18844/cjes.v15i4.5056

Brown, T. A. (2006). Confirmatory factor analysis for applied research (1st ed.). New York: Guilford Publications, Inc.

Callahan, D. (2004). The cheating culture: why more Americans are doing wrong to get ahead. San Diego: CA: Harcourt, INC.

Carpenter, D. D., Harding, T. S., Finelli, C. J., Montgomery, S. M. \& Passow, H. J. (2006). Engineering students' perceptions of and atitudes towards cheating. Journal of Engineering Education, 95(3), 181-193.

Chudzicka-Czupala, A., Grabowski, D., Mello, A. L., Kuntz, J., Zaharia, D. V., Hapon, N. \& Boru, D. (2016). Application of the theory of planned behavior in academic cheating research-cross-cultural comparison. Ethics \& Behavior, 26(8), 638-659.

Cohen, J. (1988). Statistical power analysis for the behavioral sciences (2.bs.). Hillsdale, NJ: Erlbaum.

Cokluk, O., Sekercioglu, G. \& Buyukozturk, S. (2012). Multivariate statistics for social sciences SPSS ve LISREL application. Ankara, Turkey: Pegem Akademi.

Erten, S. (2002). Research on about energy saving of intention toward the behaviour at homes for male and female students by the application of the theory of planned behaviour. Hacettepe University Journal of Education, 22, 67-73. Retrieved March 10, 2018, from http://www.efdergi.hacettepe.edu.tr/yonetim/icerik/makaleler/931-published.pdf

Fishbein, M. \& Ajzen, I. (1975). Belief, attitude, intention, and behavior: an introduction to theory and research. Reading, MA: Addison-Wesley.

Festinger, L. (1964). Behavioral support for opinion change. The Public Opinion Quarterly, 28(3), 404-417.

Fly, B. J. (1995). A study of ethical behavior of students in graduate training programs in psychology. Denver, CO: University of Denver.

Harding, T. S., Carpenter, D. D., Finelli, C. J. \& Passow, H. J. (2004). Does academic dishonesty relate to unethical behavior in professional practice? An exploratory study. Science and Engineering Ethics, 10(2), 311-324.

Harding, T. S., Mayhew, M. J., Finelli, C. J. \& Carpenter, D. D. (2007). The theory of Planned Behavior as a model of academic dishonesty in engineering and humanities undergraduates. Ethics \& Behavior, 17(3), 255279.

Hooper, D., Coughlan, J. \& Mullen, M. (2008). Structural equation modeling: Guidelines for determining model fit. The Electronic Journal of Business Research Methods, 6(1), 53-60. 
Koc, S. \& Memduhoglu, H. B., (2020). A model test towards university students' cheating behavior in the context of the theory of planned behavior. Cypriot Journal of Educational Sciences. 15(4), 727 - 748. DOI: 10.18844/cjes.v15i4.5056

Hu, L. \& Bentler, P. M. (1999). Cutoff criteria for fit indexes in covariance structure analysis: Conventional criteria versus new alternatives. Structural Equation Modeling, 6, 1-55.

Inceoglu, M. (2004). Attitude, perception communication. Ankara, Turkey: Elips Book.

Kline, R. B. (2011). Principles and practice of structural equation modeling. New York: The Guilford Press.

Kurpis, L. V., Beqiri, M. S. \& Helgeson, J. G. (2008). The effects of commitment to moral self-improvement and religiosity on ethics of business students. Journal of Business Ethics, 80, 447-463.

Lin, C. \& Wen, L. (2007). Academic dishonesty in higher education: a nationwide study in Taiwan. Higher Education, 54, 85-97.

Myers, D.G. (1993). Social psychology. New York: McGraw-Hill, Inc.

Myers, D. G. (1993). Social psychology. New York, NY: McGraw-Hill, Inc.

Nonis, S. \& Swift, C.O. (2001). An examination of the relationship between academic dishonesty and workplace dishonesty: a multicampus investigation. Journal of Education for Business, 77(2), 69-77.

Sumer, N. (2000). Structural equation modeling. Turkısh Psychological Articles, 3(6), 49-74.

Tabachnick, B. G. \& Fidell, L. S. (2007). Using multivariate statistics. MA: Allyn \& Bacon, Inc.

Yang, J. (2012). Predicting cheating behavior: a longitudinal study with Chinese business students. Social Behavior and Personality, 40(6), 933-944. 